\title{
Recombinant tissue plasminogen activator for the treatment of acute ischemic stroke
}

\author{
Jennifer M. Roth, PharmD, BCPS
}

The use of recombinant tissue plasminogen activator (rtPA) has been the standard of care for treatment of acute ischemic stroke for several years. Studies evaluating the efficacy, safety, and optimal timing of rtPA use are ongoing. Recently, results of new studies led to expansion of the short timeframe from stroke symptom onset in which a patient can receive this treatment. Additionally, more data are available to support the current goals of administration of rtPA to eligible patients as quickly as possible, as earlier treatment has been proven to improve outcomes.

C linical practice guidelines published by both the American Heart Association and American Stroke Association (AHA/ASA) in 2007, and the American College of Chest Physicians in 2008, recommend the use of the thrombolytic agent recombinant tissue plasminogen activator (rtPA) for the treatment of acute ischemic stroke (AIS) in eligible patients $(1,2)$. Approved by the US Food and Drug Administration (FDA) in 1996 for treatment of AIS, intravenous rtPA (or alteplase) is the only thrombolytic agent approved for this indication to date (3). Due to the extremely small timeframe in which a patient is eligible to receive rtPA, it is estimated that only $3 \%$ to $5 \%$ of stroke sufferers reach a hospital in time to be considered for this treatment (4). This small number is discouraging because "the ultimate goal of early reperfusion therapy is to reduce or prevent brain infarction and thereby minimize the long term disability, neurologic impairment, and stroke-related mortality" (2). As stroke is the third most frequent cause of death in the USA, killing 137,000 people each year, mortality reduction could potentially spare the lives of a large number of patients (5). This article briefly reviews the evidence supporting the use of rtPA for AIS and focuses on important new literature that has impacted practice since the publication of the current AIS guidelines.

\section{BACKGROUND}

The initial European Cooperative Acute Stroke Study (ECASS), published in 1995, studied rtPA at a higher dose $(1.1 \mathrm{mg} / \mathrm{kg}$, maximum dose $100 \mathrm{mg})$ and in a longer timeframe from stroke symptom onset (within 6 hours) than in subsequent studies, which led to currently approved and accepted rtPA dosing and usage criteria (6). The multicenter trial was conducted in 75 European hospitals and included 620 patients. In ECASS, rtPA was not found to be more effective than placebo in improving neurological outcomes at 3 months; however, post hoc analysis showed benefit in patients treated within 3 hours of stroke symptom onset, but not in those treated beyond that timeframe.

Also published in 1995, the National Institute of Neurological Disorders and Stroke rtPA Stroke Study evaluated 624 patients in the USA who were randomized to the current FDA-approved dose $(0.9 \mathrm{mg} / \mathrm{kg}$, maximum dose $90 \mathrm{mg})$ or placebo within 3 hours of stroke symptom onset (7). Patients who received rtPA were at least $30 \%$ more likely to have minimal or no disability at 3 months based on four assessment scales when compared to those in the placebo group. Symptomatic intracerebral hemorrhage (ICH) within 36 hours occurred in $6.4 \%$ of rtPA patients versus $0.6 \%$ of placebo patients $(P<0.001)$, and mortality was similar in both groups at 3 months $(P=0.30)$. Of note, half of the study patients were treated within 90 minutes of stroke symptom onset. A later subgroup analysis of the trial demonstrated that treatment with rtPA within 90 minutes of stroke symptom onset resulted in more favorable outcomes (odds ratio [OR], 2.11; 95\% confidence interval [CI], 1.33-3.55) when compared to rtPA initiated within 90 to 180 minutes (OR, 1.69; 95\% CI, 1.09-2.62) (8).

\section{EXPANDED CRITERIA FOR rtPA USE}

As mentioned above, the short 3-hour timeframe in which a patient is eligible for treatment with rtPA is a major contributing factor to the relatively small number of patients who receive this medication (4). When the European Medicines Agency approved use of rtPA in Europe in 2002, the agency requested that two follow-up studies be conducted. Conducted first, the SITS-MOST trial confirmed rtPA to be as safe and effective within 3 hours of onset of AIS in practice as in trials (9).

The second follow-up study evaluated the use of rtPA beyond the 3-hour timeframe. ECASS III, a double-blind, multicenter, parallel-group trial conducted between July 2003 and November 2007 (10), included patients 18 to 80 years of age with a clinical diagnosis of stroke who were able to receive the

From the Department of Pharmacy Services, Baylor University Medical Center at Dallas.

Corresponding author: Jennifer M. Roth, PharmD, BCPS, Department of Pharmacy Services, Baylor University Medical Center at Dallas, 3500 Gaston Avenue, Dallas, Texas 75246 (e-mail: Jennifer.Roth@BaylorHealth.edu). 
study drug within 3 to 4 hours of stroke symptom onset. After 2 years, the trial was amended to include patients treated within a 4.5-hour window, based on the results of a pooled analysis that suggested a benefit of rtPA treatment in this timeframe, as well as slow enrollment in the 3 - to 4-hour window (11). A total of 821 patients were randomized to receive either rtPA or placebo, with the primary efficacy endpoint being disability at 90 days (dichotomized as a favorable outcome [score 0 or 1] or unfavorable outcome [score 2-6]), as assessed by modified Rankin scale). As a secondary efficacy endpoint, the study evaluated a combination of global outcome measures. Safety endpoints were mortality at 90 days, any ICH, symptomatic ICH, and other adverse events. Four hundred patients were required in each group to reach $90 \%$ power to detect an OR of 1.4 for the primary endpoint. For the intentto-treat analysis, 418 patients were randomized to receive rtPA and 403 were randomized to receive placebo.

Two hundred nineteen (52.4\%) patients who received rtPA, compared to $182(45.2 \%)$ patients who received placebo, had a favorable outcome $(P$ $=0.04)$. These results were also found to be significant in the post hoc intent-to-treat analysis. Outcomes were more favorable for rtPA versus placebo for the secondary endpoint, which showed that $28 \%$ more patients in the rtPA group were able to return to an independent lifestyle. Thirty-two $(7.7 \%)$ patients in the rtPA group died, and $34(2.9 \%)$ in the placebo group died. Mortality was not signifi-

cantly different between the two groups $(P=0.68)$. ICH occurred in $27 \%$ of patients in the rtPA group versus $17.6 \%$ of patients in the placebo group $(P=0.001)$, with symptomatic ICH in $2.4 \%$ and $0.3 \%$ of each group, respectively $(P=0.008)$. The median overall time to rtPA administration was 3 hours, 59 minutes.

Concurrently, the SITS-MOST study investigators published results from their ongoing stroke registry, called SITSISTR, which also demonstrated benefit to using rtPA within 3 to 4.5 hours from stroke symptom onset (12).

Based on the results of the ECASS III and SITS-ISTR trials, the AHA/ASA published a science advisory statement in 2009 recommending that $\mathrm{rtPA}$ should be administered to eligible patients within 3 to 4.5 hours after onset of stroke symptoms (Class I, Level B evidence) (13). It is important to note, how-

Description

- Ischemic stroke onset within 3 hours of drug administration

- Measurable deficit on National Institutes of Health Stroke Scale examination

- No evidence, on computed tomography scan of the head, of hemorrhage or nonstroke cause of deficit

- Age $>18$ years

- Minor or rapidly improving symptoms

- Seizure at onset of stroke

- Stroke or serious head trauma in the last 3 months

- Major surgery in the last 14 days

- Myocardial infarction in the last 3 months

- Gastrointestinal or urinary tract hemorrhage in the last 21 days

- Known history of intracranial hemorrhage

- Suspected subarachnoid hemorrhage

- Arterial puncture at noncompressible site in the last 7 days

- Evidence of active bleeding or acute trauma (fracture) on examination

- Sustained systolic blood pressure $>185 \mathrm{~mm} \mathrm{Hg}$, diastolic blood pressure $>110 \mathrm{~mm} \mathrm{Hg}$, or aggressive treatment necessary to lower blood pressure

- On an anticoagulant, with an international normalized ratio $>1.7$ (warfarin) or elevated partial thromboplastin time (heparin)

- Platelet count $<100,000 \mathrm{uL}$

- Serum glucose $<50 \mathrm{mg} / \mathrm{dL}$ or $>400 \mathrm{mg} / \mathrm{dL}$

- Pregnancy

- Large stroke with National Institutes of Health Stroke Scale score $>22$

- Findings, on computed tomography of the head, of early infarct involving more than one third of the middle cerebral artery territory

- Age $>80$ years

- History of stroke and diabetes mellitus

- Any anticoagulant use prior to admission (even if international normalized ratio $<1.7)$

- Pretreatment stroke score $>25$

- Findings, on computed tomography of the head, of early infarct involving more than one third of the middle cerebral artery territory

ever, that the extended window for rtPA administration is not recommended for several patient populations, as there is currently no data to support its use in these patients. They include those older than 80 years; those receiving anticoagulant therapy, even with an international normalized ratio $\leq 1.7$; those with a baseline National Institutes of Health Stroke Scale score $>25$; and those with a history of both a prior stroke and diabetes. Patients meeting one or more of these criteria are not considered candidates to receive rtPA, even if otherwise eligible, if it would be initiated $>3$ hours from stroke symptom onset. (See Table for full list of indications and contraindications.)

\section{0-MINUTE D00R-T0-NEEDLE}

Current guidelines recommend that institutions treating AIS patients with rtPA do so with a goal of a door-to-needle time of 
$\leq 60$ minutes. Data from the AHA/ASA national stroke registry, Get With the Guidelines-Stroke, were evaluated by Fonarow and colleagues to determine how often door-to-needle times $\leq 60$ minutes are achieved, as well as patient and hospital characteristics and temporal trends in this patient group (with data analysis including only patients treated within 3 hours of stroke symptom onset) (14). For the time period of April 2003 through September 2009, the registry included 595,172 patients. The analysis included 25,504 patients from 1082 hospitals who presented within 3 hours of symptom onset and received rtPA (19.6\% of the 129,903 potentially eligible patients). The mean and median door-to-needle times were $79.3 \pm 28.1$ and 78 minutes, respectively. Door-to-needle times $\leq 60$ minutes were achieved in 6790 (26.6\%) patients, while the remaining 18,714 (73.4\%) patients received rtPA $>60$ minutes after arrival. Patient characteristics independently associated with door-to-needle time $\leq 60$ minutes included more severe neurological deficits, arrival during normal business hours versus off-hours, and longer onset-to-arrival time. Patient factors associated with door-to-needle times $>60$ minutes included older age, female sex, black race, a medical history of atrial fibrillation, diabetes mellitus, or prior stroke/transient ischemic attack. Hospitals with a door-to-needle time $\leq 60$ minutes had higher numbers of patients treated with rtPA annually and a lower annual number of stroke admissions.

In patients with a door-to-needle time $\leq 60$ minutes, the unadjusted mortality rate was $8.6 \%$, versus $10.4 \%$ for those in the door-to-needle $>60$ minute group $(P<0.0001)$. Overall complication rates and $\mathrm{ICH}$ rates were lower in those patients treated within 60 minutes. One of the most compelling findings of this study came from analysis of the door-to-needle time as a continuous variable in relation to in-hospital mortality. For every 15-minute reduction in door-to-needle time, there was a $5 \%$ lower odds of mortality (adjusted OR, 0.95; 95\% CI, $0.92-0.98 ; P=0.0007)$. The authors noted that these results should be interpreted cautiously, as they have not been reported previously and should be further replicated.

\section{DISCUSSION}

Since publication of the most recent guidelines for treatment of AIS in 2008, several studies have contributed to the growing body of literature supporting use of rtPA. The results of ECASS III and SITS-ISTR published in 2008, and later supported by a science advisory statement from the AHA/ASA, provided potential expanded eligibility for rtPA use. However, for several patient populations, use of rtPA 3 to 4.5 hours from stroke symptom onset has not been studied and therefore is not currently recommended.

Both previous literature and now the results of the data evaluated by Fonarow and colleagues confirm that outcomes and mortality are better in patients who receive rtPA as soon as possible after stroke symptom onset. Door-to-needle times of $\leq 60$ minutes in stroke registry patients have increased from $19.5 \%$ in 2003 to $29.1 \%$ in 2009 , an increase of about $1.6 \%$ per year (14). With more stroke centers being established and the continued focus for all stroke centers to meet the goal of timely rtPA administration, it is likely that AIS outcomes will continue to improve in the coming years.
1. Adams HP Jr, del Zoppo G, Alberts MJ, Bhatt DL, Brass L, Furlan A, Grubb RL, Higashida RT, Jauch EC, Kidwell C, Lyden PD, Morgenstern LB, Qureshi AI, Rosenwasser RH, Scott PA, Wijdicks EF; American Heart Association; American Stroke Association Stroke Council; Clinical Cardiology Council; Cardiovascular Radiology and Intervention Council; Atherosclerotic Peripheral Vascular Disease and Quality of Care Outcomes in Research Interdisciplinary Working Groups. Guidelines for the early management of adults with ischemic stroke. Stroke 2007;38(5):1655-1711.

2. Albers GW, Amarenco P, Easton JD, Sacco RL, Teal P. Antithrombotic and thrombolytic therapy for ischemic stroke: American College of Chest Physicians Evidence-Based Clinical Practice Guidelines (8th Edition). Chest 2008;133(6 Suppl):630S-669S.

3. Activase (alteplase) product information. South San Francisco, CA: Genentech, 2005 Dec.

4. American Stroke Association. Acute and preventive stroke treatments. Available at www.strokeassociation.org/STROKEORG/AboutStroke/ Treatment/Treatment_UCM_310892_Article.jsp; accessed April 6, 2011.

5. American Stroke Association. Impact of stroke. Available at www. strokeassociation.org/STROKEORG/AboutStroke/Impact-of-Stroke_ UCM_310728_Article.jsp; accessed April 6, 2011.

6. Hacke W, Kaste M, Fieschi C, Toni D, Lesaffre E, von Kummer R, Boysen G, Bluhmki E, Höxter G, Mahagne MH, et al; The European Cooperative Acute Stroke Study (ECASS). Intravenous thrombolysis with recombinant tissue plasminogen activator for acute hemispheric stroke. JAMA 1995;274(13):1017-1025.

7. National Institute of Neurological Disorders and Stroke rt-PA Stroke Study Group. Tissue plasminogen activator for acute ischemic stroke. $N$ Engl J Med 1995;333(24):1581-1587.

8. Marler JR, Tilley BC, Lu M, Brott TG, Lyden PC, Grotta JC, Broderick JP, Levine SR, Frankel MP, Horowitz SH, Haley EC Jr, Lewandowski CA, Kwiatkowski TP. Early stroke treatment associated with better outcome: the NINDS rt-PA stroke study. Neurology 2000;55(11):1649-1655.

9. Wahlgren N, Ahmed N, Dávalos A, Ford GA, Grond M, Hacke W, Hennerici MG, Kaste M, Kuelkens S, Larrue V, Lees KR, Roine RO, Soinne L, Toni D, Vanhooren G. Thrombolysis with alteplase for acute ischaemic stroke in the Safe Implementation of Thrombolysis in Stroke-Monitoring Study (SITS-MOST): an observational study. Lancet 2007;369(9558):275-282.

10. Hacke W, Kaste M, Bluhmki E, Brozman M, Dávalos A, Guidetti D, Larrue V, Lees KR, Medeghri Z, Machnig T, Schneider D, von Kummer R, Wahlgren N, Toni D; ECASS Investigators. Thrombolysis with alteplase 3 to 4.5 hours after acute ischemic stroke. $N$ Engl J Med 2008;359(13):1317-1329.

11. Hacke W, Donnan G, Fieschi C, Kaste M, von Kummer R, Broderick JP, Brott T, Frankel M, Grotta JC, Haley EC Jr, Kwiatkowski T, Levine SR, Lewandowski C, Lu M, Lyden P, Marler JR, Patel S, Tilley BC, Albers G, Bluhmki E, Wilhelm M, Hamilton S; ATLANTIS Trials Investigators; ECASS Trials Investigators; NINDS rt-PA Study Group Investigators. Association of outcome with early stroke treatment: pooled analysis of ATLANTIS, ECASS, and NINDS rt-PA stroke trials. Lancet 2004;363(9411):768-774.

12. Wahlgren N, Ahmed N, Dávalos A, Hacke W, Millán M, Muir K, Roine RO, Toni D, Lees KR; SITS investigators. Thrombolysis with alteplase 3-4.5 h after acute ischaemic stroke (SITS-ISTR): an observational study. Lancet 2008;372(9646):1303-1309.

13. Del Zoppo GJ, Saver JL, Jauch EC, Adams HP Jr; American Heart Association Stroke Council. Expansion of the time window for treatment of acute ischemic stroke with intravenous tissue plasminogen activator: a science advisory from the American Heart Association/American Stroke Association. Stroke 2009;40(8):2945-2948.

14. Fonarow GC, Smith EE, Saver JL, Reeves MJ, Bhatt DL, Grau-Sepulveda MV, Olson DM, Hernandez AF, Peterson ED, Schwamm LH. Timeliness of tissue-type plasminogen activator therapy in acute ischemic stroke: patient characteristics, hospital factors, and outcomes associated with doorto-needle times within 60 minutes. Circulation 2011;123(7):750-758. 